\title{
Achievement motive and sport participation
}

\author{
Peter Gröpel ${ }^{\mathrm{a},}$ *, Mirko Wegner ${ }^{\mathrm{b}}$, Julia Schüler ${ }^{\mathrm{c}}$ \\ a Faculty of Sport and Health Sciences, Chair of Sport Psychology, Technical University of Munich, Germany \\ ${ }^{\mathrm{b}}$ Institute for Sport Science, University of Bern, Bremgartenstrasse 140, 3012 Bern, Switzerland \\ ${ }^{\mathrm{c}}$ Institute of Sport Science, University of Konstanz, Universitatsstraße 10, 78464 Konstanz, Germany
}

Keywords:

Achievement motive

Sport participation

Implicit motive

Explicit motive

\begin{abstract}
A B S T R A C T
Three studies investigated the relationship between the achievement motive and sport participation. It was expected that both the implicit and the explicit achievement motives are positively associated with how frequently people engage in sport activities. The implicit achievement motive was assessed with indirect motive measures; the explicit achievement motive was either inferred from participants' per sonal goals or measured with self reports. Two hundred five athletes participated including college students enrolled in leisure sport programs offered at their university (Study 1), amateur athletes registered in sports clubs (Study 2), and elite tennis athletes (Study 3). The implicit achievement motive consistently predicted sport participation in all three studies. In contrast, the explicit achievement motive was uncorrelated with sport participation. The interaction between the two motives did not yield an effect on sport participation. The results indicate that the implicit, unconscious need to achieve fa cilitates regular engagement in sport activities, but the explicit, conscious orientation toward achieve ment does not. The enrichment of sports environments with incentives for the implicit achievement motive may thus attract more people to participate in sport activities.
\end{abstract}

Engaging in physical activity and sports is generally promoted for its positive effect on physical fitness (Angevaren, Aufdemkampe, Verhaar, Aleman, \& Vanhees, 2008), well being (Schulz, Meyer, \& Langguth, 2012), and health (Li \& Siegrist, 2012). Regular training is also imperative to expert performance in sports (Macnamara, Hambrick, \& Oswald, 2014; Starkes \& Ericsson, 2003). The under standing of motivation toward sport participation is thus crucial to appropriate and effective health promotion, and performance improvement. One important ingredient of motivation is achieve ment (McClelland, Atkinson, Clark, \& Lowell, 1953). Practicing in exercise health programs as well as in performance oriented sports always includes opportunities to achieve something. What an achievement in sports and exercise is, however, may range from feeling less exhausted after 10 min of walking when compared to the last week - in a health program - to mastering a kick service in tennis for the first time - in performance oriented sports. Thus, the achievement motive is of relevance for behavior change in different sport and exercise settings. The present work addressed the achievement motive as a predictor of sport participation. Sport

\footnotetext{
* Corresponding author. Chair of Sport Psychology, Technical University of Munich, Georg-Brauchle-Ring 60/62, 80992 München, Germany.

E-mail address: peter.groepel@tum.de (P. Gropel).
}

participation has been defined as the frequency of engagement in sport activities, which is typically measured on a weekly basis (Kilpatrick, Hebert, \& Bartholomew, 2005). Because sports provide ample achievement incentives, such as opportunities to improve one's skills and competing with oneself or others, it was expected that a stronger achievement motive would be associated with higher sport participation.

The achievement motive has been previously defined as a recurrent concern with surpassing standards of excellence and doing one's best (McClelland et al., 1953). People with a high achievement motive strive for testing and improving their competence (e.g., stamina in a fitness course or a technique in elite sports), and seek out challenge and competition in order to win or feel proud, whereas people with a low achievement motive tend to avoid challenging situations. Consequently, the level of achieve ment motive may significantly contribute to participation in exer cise health as well as in sport programs, as challenge, experiences and improvement of competence, and competition are involved in many kinds of sports and exercise programs. Indeed, when being asked about reasons for sport and exercise participation, people often reported on challenge and competition along with other primary motives such as improving fitness, health, and appearance (Frederick \& Ryan, 1993; Kilpatrick et al., 2005; Ryan, Frederick, 
Lepes, Rubio, \& Sheldon, 1997).

Notably, although motivation takes many forms, the above research exclusively focused on explicit, conscious motives, and ignored unconscious motivation (Frederick \& Ryan, 1993; Kilpatrick et al., 2005; Ryan et al., 1997). This is a substantial limitation because implicit, unconscious motives are better than self reported motives at predicting long term behavior (Brunstein, 2008; McClelland, Koestner, \& Weinberger, 1989). The aim of the present study therefore was to overcome this limitation and extend the prior research on motivation by examining how both the explicit and implicit motive to achieve contribute to sport participation.

The implicit achievement motive is a stable, enduring motiva tional disposition to do things well, which is based on affects and operates largely outside of a person's awareness (McClelland et al., 1989). It is aroused by task inherent achievement incentives promising rewarding emotions, such as enjoyment and pride upon mastering a challenging task. These task inherent, activity in centives include challenge (moderate task risk), task contingency, achievement work content, and time pressure (Brunstein, 2008; Spangler, 1992). Feeling proud after having mastered a chal lenging task in turn rewards the performed activity (e.g., doing sports) and therefore enhances the probability to behave similarly in the future. Brunstein and Maier (2005) reported that, depending on the strengths of their implicit achievement motives, individuals put more effort into practicing a concentration task. They argued that the implicit achievement motive is aroused by the opportunity to improve one's performance in a task relative to previous achievements (see also Brunstein \& Hoyer, 2002). Because the implicit achievement motive is not consciously represented, it is assessed indirectly by the use of projective tests, in which persons are typically asked to write stories in response to a set of picture cues (Schultheiss \& Pang, 2007).

In contrast to the implicit achievement motive, the explicit achievement motive is based on cognitive evaluations of the self and is part of the individual's self concept (McClelland et al., 1989). It includes conscious perceptions of whether achievement is impor tant to the individual and of whether achievement is valued by the individual's social environment (Brunstein \& Maier, 2005). This will result in respective conscious personal goal setting (Brunstein, 2008). The explicit achievement motive is aroused by social achievement incentives that include external rewards for achievement, challenging goals set by other persons (e.g., a boss) or by a group, achievement oriented instructions, and achievement work norms and expectancies (McClelland et al., 1989; Spangler, 1992). Anticipating rewards after having accomplished an achievement goal in turn enhances the probability to initiate the goal oriented behavior. An aroused explicit achievement motive thus affects an activity because of the perceived value of that ac tivity (McClelland, 1980). The explicit achievement motive is commonly measured by self reports.

\section{Implicit and explicit achievement motives and sport participation}

Motives per se do not affect behavior; they only drive behavior if they are aroused by incentives (McClelland, 1980). Having repeat edly found that projective tests and self reports used to measure the achievement motive seldom correlate with each other (see Koellner \& Schultheiss, 2014; Spangler, 1992; for meta analysis; Schüler, Brandstatter, Wegner, \& Baumann, 2015), McClelland et al. (1989) concluded that implicit and explicit achievement motives are two independent motive systems that interact with specific classes of incentives. The implicit achievement motive in teracts with activity achievement incentives but not social in centives, and the explicit achievement motive interacts with social achievement incentives but not activity incentives. In other words, people high in implicit achievement motive seek out an achieve ment task because they enjoy performing the task which includes activity incentives such as feeling proud and experiencing progress. According to a definition of implicit motives as the "capacity to experience the attainment of a certain type of incentive as rewarding" (Schultheiss \& Hale, 2007, p. 13), individuals high in the implicit achievement motive benefit more strongly from feeling proud and competent than individuals low in the implicit achievement motive. In contrast, people high in the explicit achievement motive seek out the task because achievement is part of their consciously reflected self concept. Therefore, not affects (e.g., pride), but social evaluative incentives such as praise and appreciation are important to them.

Sports provide ample achievement incentives, both activity and social. Activity incentives usually include challenge, time pressure, testing one's own limits and improving oneself over time, and social incentives include expectancies on and rewards for high sport achievements, such as a good grade in physical education classes, praise from peers, better ranking position, or money. Therefore, people who are high in the achievement motive (both implicit and explicit) should be more likely to frequently engage in sport activities than people who are low in the achievement motive. Our first hy pothesis was that both the implicit and the explicit achievement motives are positively associated with sport participation.

\section{Congruence between implicit and explicit achievement motives}

Because implicit and explicit motives are two independent motive systems, they may conflict and undercut, as well as combine and facilitate behavior (Baumann, Kaschel, \& Kuhl, 2005; McClelland et al., 1989; Schüler, Job, Frohlich, \& Brandstatter, 2009). Researchers have assumed that the combination of a high implicit and a high explicit motive results in higher task motivation than the incongruence between or low levels of implicit and explicit motives (e.g., Brunstein \& Maier, 2005; Kehr, 2004b; McClelland et al., 1989). In other words, persons who express a desire to act in a certain way and regularly do so presumably experience motive congruence (high levels of both implicit and explicit motive), whereas persons who seem unable to act in accordance with the desire presumably experience motive incongruence.

Empirical evidence indicates that the congruence between im plicit and explicit motives predicts well being (Baumann et al., 2005; Gropel, 2008; Kehr, 2004a), flow experience (Rheinberg, 2008; Schüler, 2010), and immediate behavior (Brunstein \& Maier, 2005). In the present research, we examined whether the congruence between implicit and explicit motive also predicts long term behavior (here: sport participation). If the combination of a high implicit and a high explicit motive enhances task moti vation, then people high in both the implicit and the explicit achievement motive should engage more frequently in sport ac tivities than people low in either the implicit and/or the explicit achievement motive. Thus, our second hypothesis was that the congruence between a high implicit and a high explicit achieve ment motive predicts sport participation.

\section{The present research}

Three separate studies tested the two hypotheses introduced above. In order to illustrate that the achievement motive sports participation link can be found over different expertise levels, participants were recruited among college students enrolled in a leisure sport program offered at their university (Study 1), amateur 
athletes registered in sport clubs (Study 2), and elite athletes (Study 3 ). We assumed that leisure, amateur, and elite sport settings consistently involve incentives for the achievement motive. These settings all allow, for example, receiving performance feedback, feeling competent, comparing one's performance with one's pre vious performance or with others.

The implicit achievement motive was assessed using different indirect motive measures. ${ }^{1}$ In particular, Study 1 employed the Multi Motive Grid (MMG; Sokolowski, Schmalt, Langens, \& Puca, 2000), Study 2 employed the Picture Story Exercise (PSE; Schultheiss \& Pang, 2007), and Study 3 employed the Operant Motive Test (OMT; Kuhl \& Scheffer, 1999). All three measures are standard measures of the implicit achievement motive, which use picture cues that allow for the motive related interpretation of the perceptual input (Baumann, Kazén, \& Kuhl, 2010). They show some variation in the degree of details presented in the picture cues (PSE: photographs, MMG \& OMT: line drawings), the response format (MMG: agree or disagree with pre formulated questionnaire items, OMT: write short statements in response to pre formulated ques tions, PSE: write free entirely imaginative stories), and scoring categories/rules (for a review see, Schüler et al., 2015). The explicit achievement motive was either inferred from participants' per sonal goals (Study 2; a measure previously used by Baumann et al., 2005) or measured with Jackson's (1999) Personality Research Form (PRF). Sport participation was operationalized as the number of days or hours per week a person engages in sport activities. The studies were conducted in accordance with the ethical principles of the American Psychological Association and were approved by the local ethics boards.

\section{Study 1}

\subsection{Method}

Participants. 112 college students ( 88 women) with a mean age of 20.0 years ( $S D \quad 3.82$ ) enrolled in the university leisure sports program participated in the study. The study was performed during the semester when students attended classes and the sports pro gram regularly took place.

Measures. Participants' implicit achievement motive was measured using the Multi Motive Grid (MMG; Sokolowski et al., 2000). The MMG is a semiprojective measure to assess implicit motives. It includes ambiguous pictures in which the participant has to choose whether a set of statements worded in the third person characterizes the displayed situation. Examples of achievement statements are "Feeling good about one's compe tence", or "Feeling confident to succeed at this task". The MMG allows for measuring the hope and fear components of the achievement, affiliation and power motive simultaneously (e.g., for achievement: hope of success and fear of failure). For the purpose of the present study, we calculated the hope of success score by summing up the respective scores for 14 pictures. In the present study, implicit achievement motive scores ranged from 0 to 12 (M 6.94, SD 2.38, Cronbach's Alpha 0.65). Prior research confirmed the reliability and validity of the MMG (Kehr, 2004a; Puca \& Schmalt, 1999; Sokolowski et al., 2000).

The explicit achievement motive was measured using the achievement scale of the Personality Research Form (PRF; Jackson, 1999). The scale consists of 16 statements (e.g., "I often set goals

\footnotetext{
1 The three single studies were conducted in the authors' different research groups independent of each other. In their individual research groups, different implicit and explicit motive measures were used following different research traditions.
}

that are difficult to reach") with which participants can either agree or which they can reject. An explicit achievement motive score was computed by summing up the items with which the participant had agreed. In the present study, the explicit achievement motive scores ranged from 1 to 15 ( $M \quad 10.24, S D \quad 3.06)$. Cronbach's Alpha in the present study was $\alpha \quad 0.69$. The achievement PRF subscale captures, at the level of self reported motivational needs, the same achievement related motivational themes as Winter's (1994) sys tem and is commonly used as a contrast measure to the implicit achievement motive (e.g., Kehr, 2004a; Schultheiss, Yankova, Dirlikov, \& Schad, 2009; Schüler, 2010).

Sport participation was measured with a single frequency item, "Please indicate how many days per week you participate in sport". Participants reported the number of days per week in which they engage in sport activities.

\subsection{Results and brief discussion}

Descriptive analysis revealed that the mean sport participation was 2.78 days per week ( $S D$ 1.67). In order to test whether the implicit and explicit achievement motive scores are related with sport participation, we conducted correlational analyses (Pearson, two tailed). The implicit achievement motive was significantly correlated with sport participation, $r \quad 0.23, p \quad 0.02$, indicating that higher implicit achievement motives were associated with higher number of days per week in which participants do sports. In contrast, the explicit achievement motive was uncorrelated with sport participation, $r \quad 0.07, p \quad 0.44$. Thus, the first hypothesis could only be supported for the implicit achievement motive. In addition, implicit and explicit achievement motives were uncor related, $r \quad 0.17, p \quad 0.07$.

We predicted further that the congruence between a high im plicit and a high explicit achievement motive is related to sport participation. To test this hypothesis, we first computed the inter action term by multiplying the $\mathrm{z}$ transformed implicit and explicit achievement motive scores. We then conducted a hierarchical multiple regression analysis on sport participation. The implicit achievement motive and the explicit achievement motive scores were entered as the first step, and their interaction term was added as the second step into the regression equation. As hypothesized, the analysis revealed a significant main effect of the implicit achievement motive, $\beta \quad 0.23, p \quad 0.02$. The main effect of the explicit achievement motive and the interaction were not signifi cant (for details see Table 1).

Summing up, in accordance with our first hypothesis, the im plicit achievement motive was positively related to sport partici pation. However, it was unexpected that the explicit motive was unrelated to the number of sport sessions per week. We also did not hypothesize that the implicit $\times$ explicit motive interaction was not significant. Before we will discuss the expected and unexpected results in the general discussion, we will test the stability of this result pattern in two further studies. Furthermore, in order to enhance the generalizability of the result, we used different sam ples and we varied the methods to assess the implicit and explicit achievement motives in the following studies.

\section{Study 2}

Study 2 was a conceptual replication of Study 1 with a sample of amateur athletes registered in sports clubs. 
Table 1

Results of the hierarchical regression analysis on sport participation (study 1 ).

\begin{tabular}{llllll}
\hline & $B$ & $S E B$ & $\beta$ & $R^{2}$ & $\Delta R^{2}$ \\
\hline Step 1 & & & & $0.06^{*}$ & \\
$\quad$ Implicit Achievement Motive & 0.42 & 0.17 & $0.25^{*}$ & & \\
$\quad$ Explicit Achievement Motive & 0.05 & 0.17 & 0.03 & & \\
Step 2 & & & & 0.07 & 0.01 \\
$\quad$ Implicit Achievement Motive & 0.40 & 0.17 & $0.23^{*}$ & & \\
$\quad$ Explicit Achievement Motive & 0.05 & 0.17 & 0.03 & & \\
$\quad$ Interaction & -0.13 & 0.15 & -0.09 & & \\
\hline
\end{tabular}

Note. B unstandardized coefficients; SEB standard errors of unstandardized coefficients for the variables in the final regression equation; $\beta$ standardized coefficients; $R^{2}\left(\Delta R^{2}\right) \quad$ cumulative (change in) variance accounted for at each step. ${ }^{*} p<0.05 ;{ }^{* *} p<0.01$.

\subsection{Method}

Participants. Sixty three amateur athletes (31 women) from various sport clubs in Munich, Germany participated in this study. ${ }^{2}$ Their mean age was 28.7 years (SD 10.25). The participants per formed 30 different kinds of sports. The majority of athletes ( $n$ 44) performed individual sports such as tennis, triathlon, or gymnastics, while the rest performed team sports like basketball, volleyball, or soccer. Among the participants, 43 athletes reported on participating regularly in amateur competitions. The data were collected in athletes' respective season time.

Measures. The implicit achievement motive was measured us ing the Picture Story Exercise (PSE; Schultheiss \& Pang, 2007). Participants wrote imaginative stories about each of six pictures according to the standard instructions used in research on implicit motives (Smith, 1992). In the order administered, the pictures depicted (1) a ship captain talking to a passenger, (2) a couple sitting on a bench by a river, (3) two female scientists working in a laboratory, (4) a man sitting at an office desk, (5) a man and a woman on a trapeze, and (6) a man, a woman and a guitar player in a bar. Two trained scorers coded all PSE protocols according to Winter's (1994) Manual for Scoring Motive Imagery in Running Text. Interrater category agreement (cf. Brunstein \& Maier, 2005) was .83. Scoring disagreements were discussed and solved by consensus. Raw motive scores were corrected for protocol length by using regression (Smith, Feld, \& Franz, 1992). Prior research sup ported the adequate validity and test retest reliability of the PSE (cf. Schultheiss \& Pang, 2007).

The explicit achievement motive was inferred from participants' personal goals using the procedure adopted from Baumann et al. (2005, Study 3). Participants were asked to generate up to ten personal goals that they intend to pursue in the near future and to indicate whether each goal is more related to achievement, affili ation, or power. Each motivational area (achievement, affiliation, and power) was illustrated by a number of examples. An explicit achievement motive score was computed by subtracting the number of achievement related goals from the total number of goals set (Job, Langens, \& Brandstatter, 2009). Hence, the higher the

\footnotetext{
${ }^{2}$ The data were collected as part of a broader research project on implicit and explicit motives, and the data set used in Study 2 was also used by Gropel, Schoene, and Wegner (2015, Study 1). Descriptive data on the implicit and explicit achievement motives are reported there. Gropel et al. examined motivational profiles of performance and recreational athletes. In particular, they tested whether the strength of implicit and explicit achievement, affiliation, and power motives differs within and between the groups of athletes. They found that performance athletes, i.e. those who practice at least three times pro week, more than $10 \mathrm{~h}$ pro week, and regularly participate in competitions, had higher implicit and explicit achievement motives and lower explicit power motive than recreational athletes. In the present Study 2, we tested whether there is a linear relationship between the implicit and explicit achievement motives, and their congruence at the one side and the number of athletes' practice days on the other.
}

proportion of achievement related goals, the higher the person's explicit motives. This procedure is in line with the notion of McClelland et al. (1989) that explicit motives are allied to explicit goals.

Sport participation was measured with the same single item as in Study 1. Participants reported the number of days per week in which they engage in sport activities.

\subsection{Results and brief discussion}

The mean sport participation was 4.44 days per week (SD 1.23). In line with our prediction, sport participation was significantly correlated with the implicit achievement motive, $r \quad 0.33, p \quad 0.01$. In contrast to expectation, however, sport participation was uncorrelated with the explicit achievement motive, $r \quad 0.19, p \quad 0.14$. Thus, as in Study 1, the first hypothesis could only be supported for the implicit achievement motive. The implicit and the explicit achievement motive scores were uncor related with each other. ${ }^{3}$

The second hypothesis predicted that the congruence between a high implicit and a high explicit achievement motive is related to sport participation. As in Study 1, a hierarchical multiple regression analysis with the implicit and the explicit achievement motive score and their interaction was conducted on sport participation. The analysis revealed a significant main effect of the implicit achievement motive and a non significant main effect of the explicit achievement motive (see Table 2). In contrast to the hy pothesis, again, the interaction was not significant.

In sum, the results of Study 2 are similar to those of Study 1 . We found a positive relationship between the implicit achievement motive and sport participation. In contrast, again, the explicit achievement motive was not related to sport participation. A possible explanation is that samples like students or amateur ath letes especially seek activity incentives (e.g., mastering challenge, improving oneself over time), whereas social incentives such as rank position and rewards are less relevant to them as their pro fessional life presumably does not depend on their achievements in sports. Note that activity incentives arouse the implicit achieve ment motive and social incentives arouse the explicit achievement motive (Spangler, 1992). But what if persons who want to have a career as a professional athlete were analyzed? One may expect that social incentives would be highly relevant for those persons. Consequently, the explicit achievement motive should be related to their practice time. To test this proposition, we sampled elite ath letes in Study 3.

\section{Study 3}

Study 3 sought to test the relationship between implicit and explicit achievement motives and sport participation among elite tennis players. Because semi professional athletes usually engage in sport activities almost every day of the week, we measured the total number of practice hours per week instead of the number of days per week in order to increase variance. Athletes' amount of practice hours were assessed one month following the start of the season.

\footnotetext{
3 This correlation was reported by Gropel et al. (2015, Study 1).
} 
Table 2

Results of the hierarchical regression analysis on sport participation (study 2).

\begin{tabular}{llllll}
\hline & $B$ & SEB & $\beta$ & $R^{2}$ & $\Delta R^{2}$ \\
\hline Step 1 & & & & $0.14^{* *}$ & \\
$\quad$ Implicit Achievement Motive & 0.32 & 0.12 & $0.32^{* *}$ & & \\
$\quad$ Explicit Achievement Motive & 0.20 & 0.12 & 0.20 & & \\
Step 2 & & & & $0.16^{*}$ & 0.01 \\
$\quad$ Implicit Achievement Motive & 0.33 & 0.12 & $0.33^{* *}$ & & \\
$\quad$ Explicit Achievement Motive & 0.19 & 0.12 & 0.19 & & \\
$\quad$ Interaction & -0.14 & 0.15 & -0.12 & & \\
\hline
\end{tabular}

Note. B unstandardized coefficients; SEB standard errors of unstandardized coefficients for the variables in the final regression equation; $\beta$ standardized coefficients; $R^{2}\left(\Delta R^{2}\right) \quad$ cumulative (change in) variance accounted for at each step. ${ }^{*} p<0.05 ;{ }^{* *} p<0.01$.

\subsection{Method}

Participants. Thirty male elite tennis players ${ }^{4}$ from the first and second German tennis Bundesliga participated in this study. ${ }^{5}$ On average, athletes were 29.9 ( $S D \quad 4.5$ ) years old. They had been playing tennis for $M \quad 19.2$ ( $S D \quad 4.81$ ) years. Athletes' best ATP ranking was $M d n 281$.

Measures. The implicit achievement motive was assessed using the Operant Motive Test (OMT; Kuhl \& Scheffer, 1999). The test includes 15 pictures of outlines of one or several persons. Four questions have to be answered in note form for each picture. These questions are: "What is important for the person in this situation and what is the person doing?", "How does the person feel?", "Why does the person feel this way?", and "How does the story end?". The responses for achievement motive content were coded by two expert raters according to the OMT manual (Kuhl \& Scheffer, 1999). Their interrater reliability was 0.86 . Implicit achievement motive scores ranged from 1 to $5\left(\begin{array}{lll}M & 2.79, S D & 1.13\end{array}\right)$. The OMT has previously been shown to be a valid and reliable measure of the implicit achievement motive (Baumann et al., 2005; Scheffer, Kuhl, \& Eichstaedt, 2003; Wegner \& Teubel, 2014).

The explicit achievement motive was measured with the same measure as in Study 1. In the present study, explicit achievement motive scores ranged from 7 to $15\left(\begin{array}{lll}M & 11.57, S D & 2.27\end{array}\right)$. The in ternal consistency of the scale was 0.70 .

Sport participation was operationalized as the sum of the practice hours per week. Participants reported their practice hours by answering the item "How many hours per week do you practice at present?".

\subsection{Results and brief discussion}

The mean practice time was $11.60 \mathrm{~h}$ per week $(S D \quad 9.80)$. This index correlated significantly with the implicit achievement motive, $r \quad 0.58, p \quad 0.001$. In contrast, similar to Studies 1 and 2, the amount of practice hours per week was uncorrelated with the

\footnotetext{
${ }^{4}$ Using the statistical software $G^{*}$ Power (Faul, Erdfelder, Buchner, \& Lang, 2009), an a priori calculation of required sample size based on a 2-sided alpha of 0.05 , a power of 0.80 , and a middle effect size $\left(f^{2} \quad 0.20\right)$ resulted in a sample size of 52 participants for the regression analysis with 2 predictor variables (i.e., implicit achievement motive and explicit achievement motive) and a sample size of 59 participants for the analysis including 3 predictor variables (i.e., implicit and explicit achievement motives and their interaction term). Because Study 3 included less participants than the required sample size, a post-hoc power calculation was performed. This power analysis revealed high and sufficient power of 0.99 . The statistical power remained sufficient even if the effect of the covariate "age" was not included (power 0.84).

${ }^{5}$ The data was also collected as part of a broader research project on implicit and explicit motives. Parts of the data set used in Study 3 not related to the achievement motive were previously reported by Wegner, Bohnacker, Mempel, Teubel, and Schüler (2014) and Wegner, Wieland, and Mempel (2016).
}

explicit achievement motive, $r \quad 0.15, p \quad 0.42$. In addition, the implicit and the explicit achievement motive scores were uncor related with each other, $r \quad 0.02, p \quad 0.91$.

We further conducted a hierarchical multiple regression anal ysis with the implicit and the explicit achievement motive scores (step 2), and their interaction on practice hours (step 3). We also controlled for participants' age (step 1 ) because it was significantly related to practice hours. Older athletes reported fewer practice hours, $r \quad 0.46, p \quad 0.01$. Similar to Studies 1 and 2, the analysis only revealed a significant main effect of implicit achievement motive. Neither the main effect of explicit achievement motive nor the implicit $\times$ explicit motive interaction were significant (see Table 3). Controlling for athletes' experience (years of playing) and ATP ranking in the above analyses did not significantly affect any of the results.

Summing up, Study 3 replicated the relationship between the implicit achievement motive and sport participation found in Studies 1 and 2 . The amount of practice hours was positively related to the implicit achievement motive scores in the sample of elite athletes. This means that the higher the participants' implicit achievement motive was the more they were currently practicing for their sport. In contrast to the expectation that social incentives such as rewards and rank position are essential for elite athletes, the explicit achievement motive scores were uncorrelated with sport participation.

\section{General discussion}

Three studies investigated the relationship between the achievement motive and sport participation. It was expected that both the implicit and the explicit achievement motives are posi tively associated with how frequently people engage in sport ac tivities. We found that the implicit achievement motive consistently predicted sport participation. Persons high in the im plicit achievement motive engaged in sport activities more frequently than persons low in the implicit achievement motive. In contrast to expectations, however, the explicit achievement motive was uncorrelated with sport participation in all three studies. Taken together, these results indicate that the implicit, unconscious need to achieve facilitates regular engagement in sport activities, but not so the explicit, conscious orientation toward achievement and setting achievement goals.

Further, we hypothesized that the congruence between implicit and explicit achievement motives predicts sport participation. In particular, we tested whether persons high in both the implicit and the explicit achievement motives engage in sport activities more frequently than persons low in either the implicit or the explicit achievement motive or both. We did not find any evidence sup porting this hypothesis in our studies. Thus, although the motiva tional congruence may promote well being and flow experience while engaging in sport activities (Rheinberg, 2008; Schüler, 2010), it need not necessarily contribute to how frequently people participate in sports.

Our findings appear quite robust. We found the same pattern of results three times despite different motive measures in a total of 205 athletes. In the three studies, we measured the implicit achievement motive with the Multi Motive Grid (Sokolowski et al., 2000), the Picture Story Exercise (Schultheiss \& Pang, 2007), and the Operant Motive Test (Kuhl \& Scheffer, 1999), which are all standard tests of implicit motives. The explicit achievement motive was measured with either self reports or inferred from partici pants' personal goals, which are both well established procedures in research on explicit motives. We used both student and nonstudent samples, including athletes at both the amateur and the elite levels of performance. In each study, the implicit 
Table 3

Results of the hierarchical regression analysis on sport participation (study 3 ).

\begin{tabular}{llllll}
\hline & $B$ & $S E B$ & $\beta$ & $R^{2}$ & $\Delta R^{2}$ \\
\hline Step 1 & & & & $0.21^{* *}$ & \\
$\quad$ Age & -0.98 & 0.36 & $-0.46^{* *}$ & & \\
Step 2 & & & & $0.52^{* *}$ & $0.32^{* *}$ \\
$\quad$ Age & -0.87 & 0.30 & $-0.40^{* *}$ & & \\
$\quad$ Implicit Achievement Motive & 4.59 & 1.19 & $0.53^{* *}$ & & \\
$\quad$ Explicit Achievement Motive & -0.93 & 0.59 & -0.22 & & \\
Step 3 & & & & $0.53^{* *}$ & 0.004 \\
Age & -0.85 & 0.31 & $-0.39^{* *}$ & & \\
$\quad$ Implicit Achievement Motive & 4.31 & 1.34 & $0.50^{* *}$ & & \\
$\quad$ Explicit Achievement Motive & -0.93 & 0.60 & -0.21 & & \\
$\quad$ Interaction & -0.67 & 1.38 & -0.08 & & \\
\hline
\end{tabular}

Note. B unstandardized coefficients; SEB standard errors of unstandardized coefficients for the variables in the final regression equation; $\beta$ standardized coefficients; $R^{2}\left(\Delta R^{2}\right) \quad$ cumulative (change in) variance accounted for at each step. ${ }^{*} p<0.05 ;{ }^{* *} p<0.01$.

achievement motive was positively associated with sport partici pation, whereas the explicit achievement motive and the congru ence between the two motives were unrelated to sport participation.

The finding that the implicit achievement motive contributes to sport participation extends previous research on motivation for physical activity, which exclusively focused on individuals' conscious reasons for sport participation. It had been shown that people participate in sport activities primarily because of feeling competent, enjoying competition, and having fun, whereas factors such as appearance, health, or fitness were less relevant (Frederick \& Ryan, 1993; Kilpatrick et al., 2005; Ryan et al., 1997). We validated and extended this line of research by showing that the implicit, unconscious motivation also plays a role. The desire for competition and enjoyment seems to originate in implicit motivation which is related to inherent aspects of an activity and affects behavior because of the enjoyment derived from the activity itself (cf. McClelland, 1980) and because of the affective change experienced (McClelland et al., 1989; Schultheiss, 2008). In accordance with previous research (Kilpatrick et al., 2005; Ryan et al., 1997), our results suggest that people are likely to participate in sports espe cially for task inherent reasons, such as enjoyment and challenge.

The relationship between the implicit achievement motive and sport participation is consistent with McClelland's (1980; McClelland et al., 1989) theory that implicit motives have greater validity for predicting long term trends in behavior than explicit motives. In contrast, explicit motives are better than implicit mo tives at predicting immediate responses to specific situations or choice behavior. Spangler (1992) conducted a meta analysis that included a wide array of long term real world behaviors such as enrollment in an academic honors program, final exam persistence, grade point average, income earned, or career success. He found that the average correlation between these outcomes and the im plicit achievement motive ranged from 0.19 to 0.22 , whereas the average correlation with the explicit achievement motive was lower, ranging from 0.13 to 0.15 . Insofar as we sampled individuals that were registered athletes (especially those in Studies 2 and 3), the index of sport participation in these samples presumably in dicates long term rather than short term or immediate behavior. One reason for this might be that, in contrast to the explicit achievement motive, the implicit achievement motive possesses an affect base which contributes to amplifying and strengthening behavior that previously led to the experience of positive affect and the satisfaction of the achievement motive (McClelland et al., 1989; Schultheiss, 2008). On the basis of our findings, it can be assumed that this affective experience is more important for long term sports related behavior than a person's evaluations of what is valued and expected in his/her social environment.

McClelland's (1980) theory also helps to explain the missing relationship between the explicit achievement motive and sport participation in the present research. Explicit motives are supposed to be related to immediate responses and choice behavior rather than to long term behavior. For example, the explicit achievement motive predicted setting higher levels of achievement aspiration (cf. McClelland et al., 1989) and choosing more challenging goal distances in golf (Elbe, Wenhold, \& Müller, 2005), handball, basketball, and soccer (Wegner \& Teubel, 2014). As noted above, it is likely that sport participation in our research represented a long term rather than short term trend in an individual's behavior. Therefore, the explicit achievement motive was unrelated to sport participation in our studies. However, it may be assumed that the explicit achievement motive would predict whether or not people choose participation in sports in favor of other leisure time activities.

The congruence between the implicit and the explicit achieve ment motive deserves mention. The expected interaction effect was not observed in the present research, indicating that the implicit achievement motive predicted sport participation regardless of whether the explicit achievement motive was high or low. Kehr's (2004b) compensatory model of motivation and volition may provide an explanation for this finding. According to this model, the discrepancy between implicit and explicit motives reduces task motivation, but people compensate for it by exerting volition. In line with this, Gropel and Kehr (2014) found that individuals who were asked to complete tasks incongruent with their implicit mo tives performed equally well as individuals who completed motive congruent tasks, but they subsequently showed reduced volitional resources. Thus, it is likely that volition compensated for the somewhat lowered motivation due to a weak explicit achievement motive among our participants. Future researchers may profitably examine the compensatory role of volition in sport participation.

In sum, the present results suggest that the implicit achieve ment motive has a role in predicting how frequently people do sports at both amateur and elite levels. This implies that the inherent enjoyment and fun associated with sport activities and/or the growth of competency is a salient justification for engaging in sports (see also Ryan et al., 1997). Praise from peers, ranking posi tion, or rewards, i.e. the incentives that arouse the explicit achievement motive, seem to be less relevant. The present findings thus further support the implications by Kilpatrick et al. (2005) and Ryan et al. (1997) that making physical activities more enjoyable and personally challenging may contribute to increased participa tion in sports and exercise, and the health and skill development benefits associated with this. For example, effective health pro motion may especially focus on promoting fun, challenge and the feeling of mastery associated with sport activities, rather than on creating perceived societal pressure and health fears. Similarly, the focus on positive emotions and mastery may help teachers to promote sport participation and skill development among their students. Indeed, educational programs that aimed at promoting motivation by incorporating and acknowledging students' feelings and praising the students' endeavors of mastery were effective at increasing sport participation and skill development (cf. Cheon \& Reeve, 2013).

From the present results it could also be speculated that sport programs at any expertise level include incentives for persons high in the implicit achievement motive. In elite sport, prolonged and intensive practice participation is a prerequisite for elite perfor mance. This bears certain implications for talent identification. If motivational screening is included in talent identification, mea sures of the explicit achievement motive are usually used. The present results suggest that screening for the strength of athletes' 
implicit achievement motive would benefit the identification of athletes that enjoy practicing in their sports and could increase the chance of maintained elite sports participation.

For leisure and amateur sports, the present findings could also mean that such programs should address a variety of motives including, for example, the affiliation and the power motive. Sports practice at any expertise level seems to include aspects of personal improvement and competition which attract individuals high in the implicit achievement motive. Thus, one imperative of the present findings might be that sports environments need to be enriched with incentives for other basic motives like the affiliation or the power motive to also attract persons who are not high in the im plicit achievement motive. Such incentives could be fostering social interaction in cooperative sport tasks (affiliation motive) or offering opportunities for people to help or guide others (power motive) in the framework of a given sports program. Future research could address the question of whether such enriched sports environ ments actually attract persons who have a low implicit achieve ment motive.

\section{References}

Angevaren, M., Aufdemkampe, G., Verhaar, H. J. J., Aleman, A., \& Vanhees, L. (2008). Physical activity and enhanced fitness to improve cognitive function in older people without known cognitive impairment. Cochrane Database of Systematic Reviews, 3. http://dx.doi.org/10.1002/14651858.CD005381.pub3. CD005381.

Baumann, N., Kaschel, R., \& Kuhl, J. (2005). Striving for unwanted goals: Stressdependent discrepancies between explicit and implicit achievement motives reduce subjective well-being and increase psychosomatic symptoms. Journal of Personality and Social Psychology, 89, 781799.

Baumann, N., Kazén, M., \& Kuhl, J. (2010). Implicit motives: A look from personality systems interaction theory. In O. C. Schultheiss, \& J. C. Brunstein (Eds.), Implicit motives (pp. 375 403). New York, NY: Oxford University Press.

Brunstein, J. C. (2008). Implicit and explicit motives. In J. Heckhausen, \& H. Heckhausen (Eds.), Motivation and action (pp. 221 246). Cambridge: Cambridge University Press.

Brunstein, J. C., \& Hoyer, S. (2002). Implizites versus explizites Leistungsstreben: Befunde zur Unabhangigkeit zweier Motivsysteme [Implicit versus explicit achievement motivation: Findings on the independence of two motivational systems]. Zeitschrift für Padagogische Psychologie, 16(1), 51 62. http:// dx.doi.org/10.1024//1010-0652.16.1.51.

Brunstein, J. C., \& Maier, G. W. (2005). Implicit and self-attributed motives to achieve: Two separate but interacting needs. Journal of Personality and Social Psychology, 89, 205 222. http://dx.doi.org/10.1037/0022-3514.89.2.205.

Cheon, S. H., \& Reeve, J. (2013). Do the benefits from autonomy-supportive PE teacher training programs endure? A one-year follow-up investigation. Psychology of Sport and Exercise, 14, 508 518. http://dx.doi.org/10.1016/j. psychsport.2013.02.002.

Elbe, A.-M., Wenhold, F., \& Müller, D. (2005). Zur Reliabilitat und Validitat der Achievement Motive Scale-Sport [On the reliability and validity of the Achievement Motive Scale-Sport]. Zeitschrift für Sportpsychologie, 12, 5768. http://dx.doi.org/10.1026/1612-5010.12.2.57.

Faul, F., Erdfelder, E., Buchner, A., \& Lang, A.-G. (2009). Statistical power analyses using G*Power 3.1: Tests for correlation and regression analyses. Behavior Research Methods, 41, 1149 1160. http://dx.doi.org/10.3758/BRM.41.4.1149.

Frederick, C. M., \& Ryan, R. M. (1993). Differences in motivation for sport and exercise and their relationships with participation and mental health. Journal of Sport Behavior, 16, 125145.

Gropel, P. (2008). Affect regulation and motive-incongruent goal orientations: Relation to well-being. Studia Psychologica, 50,137 146

Gropel, P., \& Kehr, H. M. (2014). Motivation and self-control: Implicit motives moderate the exertion of self-control in motive-related tasks. Journal of Personality, 82, 317 328. http://dx.doi.org/10.1111/jopy.12059.

Gropel, P., Schoene, L., \& Wegner, M. (2015). Implizite und explizite Motive von Leistungs- und Freizeitsporttreibenden [The implicit and explicit motives of high-performance and recreational athletes]. Zeitschrift für Sportpsychologie, 22, 6 19. http://dx.doi.org/10.1026/1612-5010/a000133.

Jackson, D. N. (1999). Personality research form manual (3rd ed.). New York: Research Psychologists Press.

Job, V., Langens, T. A., \& Brandstatter, V. (2009). Effects of achievement goal striving on well-being: The moderating role of the explicit achievement motive. Personality and Social Psychological Bulletin, 35, 983996.

Kehr, H. M. (2004a). Implicit/explicit motive discrepancies and volitional depletion among managers. Personality and Social Psychology Bulletin, 30, 315 327. http:/ dx.doi.org/10.1177/0146167203256967.

Kehr, H. M. (2004b). Integrating implicit motives, explicit motives, and perceived abilities: The compensatory model of work motivation and volition. Academy of Management Review, 29, $479499 . \quad$ http://dx.doi.org/10.5465/
AMR.2004.13670963

Kilpatrick, M. W., Hebert, E., \& Bartholomew, J. B. (2005). College students' motivation for physical activity: Differentiating male and female motives for sport and exercise participation. Journal of American College Health, 54, 8794.

Kollner, M. G., \& Schultheiss, O. C. (2014). Meta-analytic evidence of low convergence between implicit and explicit measures of the needs for achievement, affiliation, and power. Frontiers in Psychology: Personality and Social Psychology, 5, 826. http://dx.doi.org/10.3389/fpsyg.2014.00826.

Kuhl, J., \& Scheffer, D. (1999). Der operante multi-motiv-test (OMT): Manual [The Operant Multimotive Test (OMT): Manual]. Osnabrück, Germany: University of Osnabrück.

Li, J., \& Siegrist, J. (2012). Physical activity and risk of cardiovascular disease A meta-analysis of prospective cohort studies. International Journal of Environmental Research and Public Health, 9, 391 407. http://dx.doi.org/10.3390/ ijerph9020391.

Macnamara, B. N., Hambrick, D. Z., \& Oswald, F. L. (2014). Deliberate practice and performance in music, games, sports, education, and professions: A metaanalysis. Psychological Science. http://dx.doi.org/10.1177/0956797614535810. OnlineFirst Publication.

McClelland, D. C. (1980). Motive dispositions: The merits of operant and respondent measures. In L. Wheeler (Ed.), Review of personality and social psychology (Vol. 1, pp. 10 41). Beverly Hills, CA: Sage.

McClelland, D. C., Atkinson, J. W., Clark, R. A., \& Lowell, E. L. (1953). The achievement motive. New York: Appleton-Century-Crofts.

McClelland, D. C., Koestner, R., \& Weinberger, J. (1989). How do self-attributed and implicit motives differ? Psychological Review, 96, 690 702. http://dx.doi.org/ $10.1037 / 0033-295 \times 96.4 .690$.

Puca, R. M., \& Schmalt, H.-D. (1999). Task enjoyment: A mediator between achievement motives and performance. Motivation and Emotion, 23, 1529.

Rheinberg, F. (2008). Intrinsic motivation and flow. In J. Heckhausen, \& H. Heckhausen (Eds.), Motivation and action (pp. 323 348). Cambridge: University Press.

Ryan, R. M., Frederick, C. M., Lepes, D., Rubio, N., \& Sheldon, K. M. (1997). Intrinsic motivation and exercise adherence. International Journal of Sport Psychology, 28, 335354.

Scheffer, D., Kuhl, J., \& Eichstaedt, J. (2003). Der Operante Motiv-Test (OMT): Inhaltsklassen, Auswertung, psychometrische Kennwerte und Validierung [The Operant Motive Test (OMT): contents, scoring, psychometric values, and validation]. In J. Stiensmeier-Pelster, \& F. Rheinberg (Eds.), Diagnostik von Motivation und Selbstkonzept [Diagnostics of motivation and self-concept]. Gottingen, Germany: Hogrefe.

Schüler, J. (2010). Achievement incentives determine the effects of achievementmotive incongruence on flow experience. Motivation and Emotion, 34, 214. http://dx.doi.org/10.1007/s11031-009-9150-4.

Schüler, J., Brandstatter, V., Wegner, M., \& Baumann, N. (2015). Testing the convergent and discriminant validity of three implicit motive measures: PSE, OMT, and MMG. Motivation and Emotion, 39, 839 857. http://dx.doi.org/ 10.1007/s11031-015-9502-1.

Schüler, J., Job, V., Frohlich, S. M., \& Brandstatter, V. (2009). Dealing with a hidden stressor: Emotional disclosure as a coping strategy to overcome the negative effects of motive incongruence on health. Stress and Health, 25, 221233.

Schultheiss, O. C. (2008). Implicit motives. In O. P. John, R. W. Robins, \& L. A. Pervin (Eds.), Handbook of personality: Theory and research (3rd ed., pp. 603 633). New York: Guilford Press.

Schultheiss, O. C., \& Hale, J. (2007). Implicit motives modulate attentional orienting to facial expressions of emotion. Motivation and Emotion, 31, 13 24. http:// dx.doi.org/10.1007/s11031-006-9042-9.

Schultheiss, O. C., \& Pang, J. S. (2007). Measuring implicit motives. In R. W. Robins, R. C. Fraley, \& R. Krueger (Eds.), Handbook of research methods in personality psychology (pp. 322 344). New York: Guilford.

Schultheiss, O. C., Yankova, D., Dirlikov, B., \& Schad, D. J. (2009). Are implicit and explicit motive measures statistically independent? A fair and balanced test using the Picture Story Exercise and a cue- and response-matched questionnaire measure. Journal of Personality Assessment, 91, 72 81. http://dx.doi.org/ $10.1080 / 00223890802484456$.

Schulz, K.-H., Meyer, A., \& Langguth, N. (2012). Korperliche Aktivitat und psychische Gesundheit [Exercise and psychological well-being]. Bundesgesundheitsblatt, 55, 55 65. http://dx.doi.org/10.1007/s00103-011-1387-x.

Smith, C. P. (1992). Motivation and personality: Handbook of thematic content analysis. New York: Cambridge University Press.

Smith, C. P., Feld, S. C., \& Franz, C. E. (1992). Methodological considerations: Step in research employing content analysis systems. In C. P. Smith (Ed.), Motivation and personality: Handbook of thematic content analysis (pp. 515 536). Cambridge, MA: Cambridge University Press.

Sokolowski, K., Schmalt, H.-D., Langens, T. A., \& Puca, R. M. (2000). Assessing achievement, affiliation, and power motives all at once: The multi-motive grid (MMG). Journal of Personality Assessment, 74, 126 145. http://dx.doi.org/ 10.1207/S15327752JPA740109.

Spangler, W. D. (1992). Validity of questionnaire and TAT measures of need for achievement: Two meta-analyses. Psychological Bulletin, 112, 140 154. http:// dx.doi.org/10.1037/0033-2909.112.1.140.

Starkes, J. L., \& Ericsson, K. A. (2003). Expert performance in sport. Champaign, IL: Human Kinetics.

Wegner, M., Bohnacker, V., Mempel, G., Teubel, T., \& Schüler, J. (2014). Explicit and implicit affiliation motives predict verbal and nonverbal social behavior in 
sports competition. Psychology of Sport and Exercise, 15, 588 595. http:// dx.doi.org/10.1016/j.psychsport.2014.06.001.

Wegner, M., \& Teubel, T. (2014). The implicit achievement motive predicts match performances and the explicit motive predicts choices for target distances in team sports. International Journal of Sport Psychology, 45(6), 621 638. http:// dx.doi.org/10.7352/IJSP 2014.45.621.

Wegner, M., Wieland, A., \& Mempel, G. (2016). The implicit fear of power motive is associated with practice time in elite karateka and tennis players. International Journal of Sport and Exercise Psychology. http://dx.doi.org/10.1080/ 1612197X.2015.1094116 (2015; online first).

Winter, D. G. (1994). Manual for scoring motive imagery in running text (4th ed.). Ann Arbor, MI: Department of Psychology, University of Michigan. Unpublished manuscript. 